\title{
Effect of portal vein embolisation on the growth rate of colorectal liver metastases
}

\author{
V Pamecha', A Levene' ${ }^{2}$ F Grillo², N Woodward ${ }^{3}$, A Dhillon ${ }^{2}$ and BR Davidson*,I \\ 'Department of Hepato Pancreatico Biliary and Liver Transplant Surgery, Royal Free Hospital, University College London, London, UK; ${ }^{2}$ Department of \\ Pathology, Royal Free Hospital, University College London, London, UK; ${ }^{3}$ Department of Radiology, Royal Free Hospital, University College London, \\ London, UK
}

Portal vein embolisation (PVE) is used to increase the remnant liver volume before major liver resection for colorectal metastases. The resection rate after PVE is $60-70 \%$, mainly limited by disease progression. The effect of PVE on tumour growth rate has not been investigated. The objective of this study was to compare the growth characteristics of resected colorectal liver metastases in patients undergoing pre-operative PVE with those of matched controls who had not undergone PVE. There were 22 patients who had undergone preoperative PVE and 20 matched controls. Tumour growth rate was calculated by the change in tumour volume (CT/MRI volumetric assessment) from diagnosis to resection. Resected histological specimens were examined by two histopathologists independently for cell differentiation, percentage tumour cell necrosis and mitotic rate. Immunochemical staining with Ki67 was carried out using the MIB-I monoclonal antibody and quantified using a Glasgow cell-counting graticule. The groups were comparable in demographics, stage of primary disease, volume of liver metastases at presentation and chemotherapy received. The tumour growth rate calculated from imaging was more rapid in the PVE group compared with that in controls (control: $0.05 \pm 0.25 \mathrm{ml} \mathrm{day}^{-1}$, PVE: $0.36 \pm 0.68 \mathrm{ml} \mathrm{day}^{-1}, P=0.06$ ). Histology showed no difference in the degree of differentiation, extent of necrosis or apoptosis between the two groups. However, mitotic rate was higher post PVE, as was the proliferation index Ki67 $(P=0.04)$. This study has confirmed that tumour growth rate increased following PVE and that this is related to increased tumour cell division.

British Journal of Cancer (2009) 100, 617-622. doi:10.1038/sj.bjc.6604872 www.bjcancer.com

Published online 10 February 2009

(c) 2009 Cancer Research UK

Keywords: portal vein embolisation; colorectal liver metastases; liver resection

Portal vein embolisation (PVE) is an established technique to achieve curative resection in patients who would otherwise be advised against surgery due to an anticipated inadequate residual liver volume. The resection rate after PVE is $60-70 \%$, mainly limited by disease progression (Mueller et al, 2008; Pamecha et al, 2009). This may reflect either a rapid disease progression in patients who are selected for PVE or that PVE stimulates tumour growth. Tumour growth exceeding that of the normal liver parenchyma has been shown on imaging following PVE in patients with contra lateral lobe metastases (Elias et al, 1999), and the tumour-doubling time following PVE has been shown to be reduced from 92 to 76 days (Kokudo et al, 2001). There have been concerns that PVE may increase the risk of disease recurrence after curative resection (Kokudo et al, 2001; Pamecha et al, 2009). The influence of PVE on tumour growth characteristics on resected cancers has not been investigated. This study was designed to evaluate the effect of PVE on tumour growth and cancer-cell proliferation in patients with resected colorectal liver metastases.

*Correspondence: Professor BR Davidson;

E-mail: b.davidson@medsch.ucl.ac.uk

Presented at the Eighth World Congress of International Hepato Pancreato Biliary Association, February 2008, Mumbai, India, in the Award Oral paper session.

Received 25 July 2008; revised 8 December 2008; accepted 9 December 2008; published online 10 February 2009

\section{MATERIALS AND METHODS}

The study involved 22 patients who had undergone liver resection and had required PVE due to an inadequate anticipated residual liver volume. Over the study period (September 1999 to September 2005), 109 patients underwent major liver resection ( $\geqslant 3$ liver segments) for colorectal cancer (CRC) metastases at the centre. Eighty-seven of these patients underwent liver resection without PVE. Twenty of these 87 patients had similar tumour volumes at presentation compared with the patients undergoing PVE and were therefore selected as a non PVE control group. Clinical details of the patients were collected prospectively, including demographics, stage of the primary disease, details of the liver metastases and chemotherapy received.

\section{Volumetric measurements and tumour growth rate analysis}

Tumour volumes were measured by CT (GE Medical Systems High Speed System, Milwaukee, WI, USA) or MRI (Philips Intera 1 T System Philips, Netherlands) at the time of diagnosis. The technique for measuring volumes has been described earlier (Beal et al, 2006). Briefly, axial 10-mm sections through the liver were obtained in a single breath-hold. Using a workstation, the tumour volume was calculated by multiplying the area of each liver image by the slice thickness. An experienced hepato-biliary 
radiologist performed all the measurements. The tumour volume was also calculated from the resected specimen by measuring the three dimensions of the tumour and calculating the volume. Tumour growth was calculated $\left(\mathrm{mlday}^{-1}\right)$ by subtracting the tumour volume at diagnosis from the volume at resection and dividing by time in days. The growth rate between the two groups was compared.

\section{Histological analysis}

Resected specimens were sliced and fixed in $10 \%$ formalin for $24 \mathrm{~h}$. Protocol samples were paraffin processed and tissue sections were prepared using routine laboratory standard procedures and stained with haematoxylin and eosin. The predominant cellular differentiation and the percentage of necrosis were identified. The mitotic index and apoptotic counts were calculated in 10 high-power fields of viable tumour.

\section{Immunohistochemistry}

Proliferative activity of the tumours was assessed by using the mouse antihuman monoclonal Ki67 antibody (clone MIB-1) obtained by DAKO (Glostrup, Denmark). The antibody reacts with human Ki67 nuclear antigen which is only expressed during cell division. Sections of formalin-fixed, paraffin-embedded tissues $(3 \mathrm{~mm})$ were cut into charged slides and sections were immunostained as per protocol (microwave antigen retrieval in ethylene diamine tetraacetic acid (EDTA) buffer for $20 \mathrm{~min}$ at $850 \mathrm{~W}$, antibody concentration 1 out of 300, Novolink Polymer Detection System, Novocastra Vision Byosystems, UK). The labelling index was determined by using a Glasgow cell-counting graticule (Going, 1994). Areas where labelling was the highest were chosen and necrotic areas were avoided. The number of Ki67-positive cells was counted in 10 high-power fields and expressed as a percentage of the total number of cancer cells. Histological assessment was carried out by two experienced pathologists (A Levene and F Grillo) independently, who were blinded to the treatment group and related clinical data.

\section{Chemotherapy}

Of the 22 patients undergoing PVE, all had chemotherapy before and after the procedure. Chemotherapy post-PVE was started 2 weeks after embolisation and continued for 6 weeks or until a decision was made regarding liver resection surgery. All 20 patients in the control group received chemotherapy before the liver resection. Three patients with PVE received chemotherapy after liver resection because of involved $(n=1)$ or close $(n=2)$ resection margin (13.6\%). Two patients without PVE received chemotherapy after liver resection because of involved $(n=1)$ or close $(n=1)$ resection margin $(10 \%)$. In all cases, this comprised a standard 5FU and folinic-acid-based protocol combined with oxaliplatin or irinotican. The average number of cycles was six.

\section{Statistics}

Student $t$-tests were used to compare the data. Data are expressed as means with $95 \%$ confidence intervals and median with ranges. $P<0.05$ was considered significant. Survival rates were calculated using the Kaplan-Meier methods.

\section{RESULTS}

The patient, primary tumour and liver metastases characteristics are shown in Table 1. The groups were well matched by age, sex, primary tumour site, Duke's stage and the temporal relationship of the liver metastases (synchronous/metachronous) to the presentation of the primary.
Table I Demographics, primary tumour and liver metastases characteristics

\begin{tabular}{lccc}
\hline & $\begin{array}{c}\text { Control } \\
(\mathbf{n}=\mathbf{2 0})\end{array}$ & $\begin{array}{c}\text { PVE } \\
(\mathbf{n = 2 2})\end{array}$ & P-value \\
\hline Age (range) & $61.5(39-78)$ & $62.5(46-78)$ & 0.876 \\
Female & 9 & 10 & 0.724 \\
Dukes (B/C) & $4 / 16$ & $5 / 17$ & 0.754 \\
Rectal/colon & $6 / 14$ & $9 / 13$ & 0.213 \\
Syn/Meta & $10 / 10$ & $13 / 9$ & 0.537 \\
Ext Rt / Rt Hep & $8 / 12$ & $14 / 8$ & 0.548 \\
Number of tumours & $2(1-5)$ & $3(1-9)$ & 0.153 \\
Resection margin (mm) & $20.2 \pm 3.7$ & $14.7 \pm 4.2$ & 0.338 \\
Number of chemotherapy cycles & $6(3-10)$ & $6(3-10)$ & 0.141 \\
\hline
\end{tabular}

Syn = synchronous; Meta = metachronous; Ext Rt = extended right hepatectomy; Rt Hep $=$ right hepatectomy;PVE = portal vein embolisation.

As would be expected the volumes of liver metastases at presentation in the groups were the same (control: $81.41 \pm 57$, PVE: $81.3 \pm 88, P=0.98$ (Figure $1 \mathrm{~A})$ ). The tumour volume at resection was higher in the PVE group, but this was not significant (control: $116 \pm 77$, PVE: $149 \pm 110, P=0.19$ ) (Figure 1B). The time from presentation to resection was longer in the PVE group by an average of 33 days ( $183 \pm 88 v s 150 \pm 78, P=0.19$ ) (Figure $1 C$ ). The tumour growth rate $\left(\mathrm{ml} \mathrm{day}^{-1}\right)$ was more rapid in the PVE group compared with controls (control: $0.05 \pm 0.25$, PVE: $0.36 \pm 0.68$, $P=0.06$ ) (Figure 1D).

The morphology of the resected tumours in both groups was evaluated by assessing tumour differentiation, necrosis and apoptosis. These variables were not different between the groups (Table 2). The mitotic rate (Figure 2A) was increased following PVE as measured by both histopathologists, although statistically significant for only one (Table 2). The Ki67 proliferation index increased significantly following PVE (Table 2) (Figures 2B, 3 and 4).

A subgroup analysis was carried out comparing the tumour growth and Ki67 in patients with synchronous and metachronous metastases (Table 3). Growth rate and proliferation index were increased by PVE in both groups, but was statistically significant only in the metachronous group.

The 5 year survival of the patient group who had undergone PVE was $25 \%$ compared with $55 \%$ for the control group $(P=n s)$ (Figure 5).The median disease-free survival of patients undergoing liver resection following PVE was 12 months, and 24 months in those resected without undergoing PVE (Figure 6).

\section{DISCUSSION}

Liver resection provides the main possibility of cure in patients with colorectal liver metastases and 5-year survival ranges from 25 to $58 \%$ (Simmonds et al, 2006). One of the contraindications to hepatic resection is a small future liver remnant. The small residual liver volume can lead to cholestasis, fluid retention, impaired liver synthetic function and liver failure (Melendez et al, 2001; Schindl et al, 2005). PVE increases the anticipated future liver volume and allows surgery in patients who would otherwise be contraindicated for resection. The potential disadvantage of PVE is that earlier studies have suggested that it may stimulate tumour growth and lead to reduced long-term survival (Elias et al, 1999; Kokudo et al, 2001).

This study has examined the effect of PVE on tumour growth and morphology. The tumours grew significantly during the period between diagnosis and resection. The growth rate was significantly higher following PVE. The control group was well matched by 
A

$P=0.98$

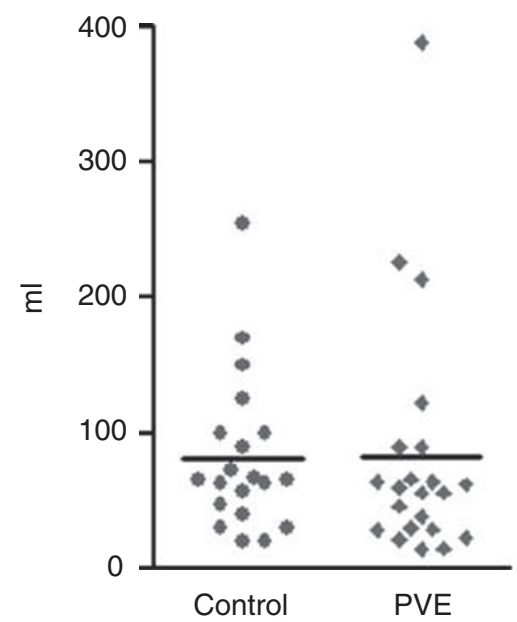

C

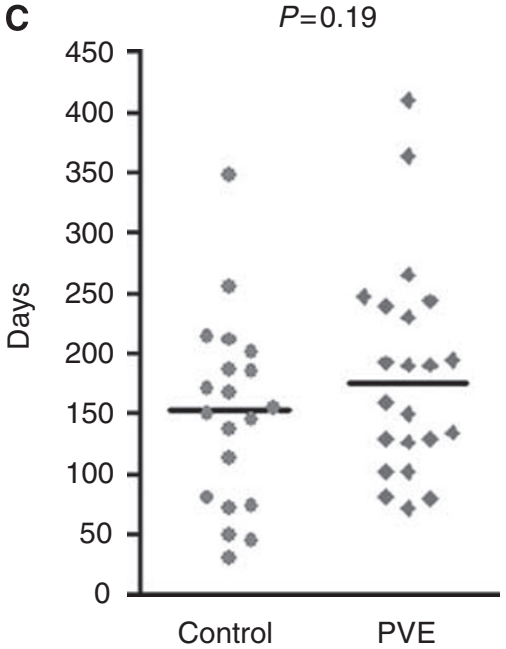

B

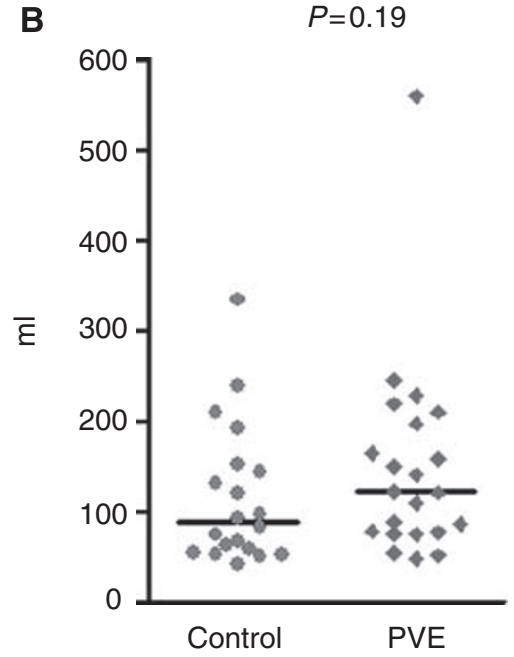

D

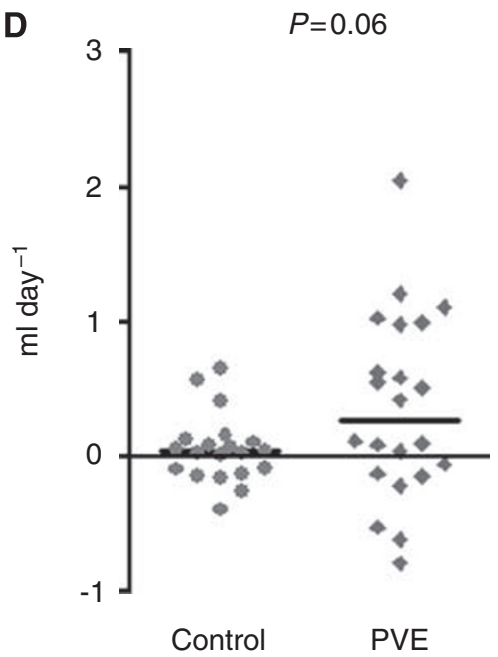

Figure I (A) Tumour volume at diagnosis. (B) Tumour volume at resection.

C) Time difference from diagnosis to resection. (D) Tumour growth rate.

tumour stage and burden;although the period between initial diagnosis and resection was longer for the PVE group (by 33 days), this was not statistically significant. This would suggest that PVE stimulates tumour growth. Any difference in the growth rates of the two groups could have been more effectively addressed by including a comparison of growth rates before PVE. However, interim CT scans were not available in the control group. Another possible explanation for the tumour volume changes following PVE would be ischemia and inflammation rather than cancer growth. However, the resected cancers showed no evidence of haemorrhage and the degree of cell necrosis and apoptosis was similar with and without PVE.

This is the first study to compare tumour growth from imaging with increased cancer-cell proliferation at the molecular level following PVE. The mitotic index is a sensitive but non specific marker of cell proliferation (Peeters et al, 2006). The mitotic index was increased in blinded assessment by both histopathologists but was statistically significant for one observer only. This interobserver variation in the mitotic index can be explained by difference in appreciation of dividing cells by the two histopathologists. The Ki67 has been shown to be more specific in assessing the cancer-cell proliferation rate (Peeters et al, 2006). The Ki67 labelling index was significantly higher in the PVE group than controls. A high Ki67 labelling index is an adverse prognostic factor in patients undergoing hepatectomy for colorectal liver metastases (Weber et al, 2001). Identification of the Ki67 labelling index before and after PVE in the same patient would have been of interest, but pre-PVE biopsy was not carried out for ethical reasons as it carries a risk of tumour seeding.

A subgroup analysis of patients with synchronous and metachronous metastases showed tumour growth rate and Ki67 to be greater post PVE for the latter. The reason for this has not been established and should be the subject of further study. It is possible that there is a biological difference between these tumours which allows PVE to have a more marked effect on growth with metachronous disease.

The increase in tumour growth following PVE could be secondary to haemodynamic changes. Portal vein embolisation increases hepatic arterial blood flow (Nagino et al, 1998; Denys et al, 2000; Yokoyama et al, 2007). As intrahepatic metastases depend solely on arterial blood supply (Archer and Gray, 1989), increased hepatic arterial flow may provide nutritional advantages for tumour growth. A correlation between tumour growth rate and arterial flow to the liver could clarify these hypotheses.

Tumour growth could be initiated by a reduction in cell apoptosis or increase in cell division (Peeters et al, 2006). Several cytokines and growth factors are known to play important roles in liver regeneration (Kusaka et al, 2006; Yokoyama et al, 2007), and could 
increase tumour growth after PVE. Mueller et al, reported, in a rat model of portal branch ligation, an association between hepatic atrophy and increased expression of genes known to promote tumour growth and angiogenesis (Mueller et al, 2003). Expression of hepatocyte growth factor (HGF)-mRNA is markedly increased after portal vein ligation (Uemura et al, 2000), which is known to stimulate growth of colorectal carcinoma cells in vitro (Ueno et al, 1996; Nabeshima et al, 1998). Negative regulators of hepatocyte proliferation, such as transforming growth factor (TGF)- $\beta 1$ (Braun et al, 1988; Kusaka et al, 2006), are strongly expressed in the

Table 2 Tumour morphology with and without PVE

\begin{tabular}{|c|c|c|c|}
\hline & $\begin{array}{l}\text { Control } \\
(n=20)\end{array}$ & $\begin{array}{c}\text { PVE } \\
(n=22)\end{array}$ & $P$-value \\
\hline \multicolumn{4}{|l|}{ Necrosis (\%) } \\
\hline Median & $35(15-95)$ & $45(10-95)$ & \\
\hline Mean \pm s.d. & $39.5 \pm 4.9$ & $37.7 \pm 4.8$ & 0.801 \\
\hline \multicolumn{4}{|l|}{ Apoptosis/lo hpf } \\
\hline Median & $188(54-327)$ & $132(68-350)$ & \\
\hline Mean \pm s.d. & $178 \pm 87$ & $147 \pm 69$ & 0.212 \\
\hline \multicolumn{4}{|c|}{ Mitotic count/IO hpf } \\
\hline \multicolumn{4}{|c|}{ Observer I } \\
\hline Median & $9(3-19)$ & II (4-22) & 0.404 \\
\hline Mean \pm s.d. & $10.5 \pm 1.0$ & $11.8 \pm 1.1$ & \\
\hline \multicolumn{4}{|l|}{ Observer 2} \\
\hline Median & $9(3-24)$ & $14(3-35)$ & \\
\hline Mean \pm s.d. & $9.7 \pm 5.0$ & $16.1 \pm 8.8$ & 0.009 \\
\hline \multicolumn{4}{|l|}{ Ki67 (\%) } \\
\hline \multicolumn{4}{|l|}{ Observer I } \\
\hline Median & $29(3-48)$ & $36(6-75)$ & \\
\hline Mean \pm s.d. & $22.6 \pm 2.2$ & $36.7 \pm 3.8$ & 0.048 \\
\hline \multicolumn{4}{|l|}{ Observer 2} \\
\hline Median & $38(11-62)$ & $47(15-93)$ & \\
\hline Mean \pm s.d. & $37.8 \pm 13.8$ & $48.9 \pm 18.9$ & 0.046 \\
\hline
\end{tabular}

$\mathrm{PVE}=$ portal vein embolisation

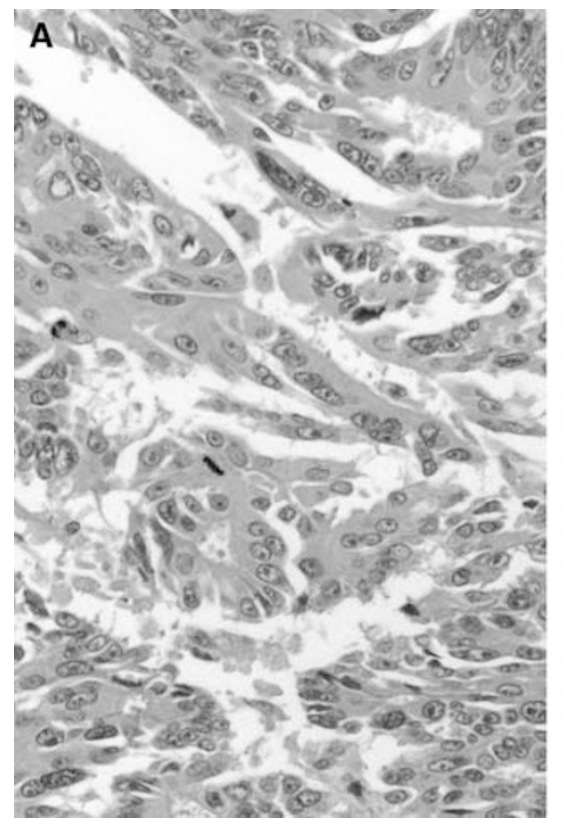

ligated lobe (Uemura et al, 2000; Kusaka et al, 2006) and these may contribute to increased cancer-cell proliferation.

The survival analysis showed excellent long-term survival in patients undergoing major liver resection for CRC metastases with
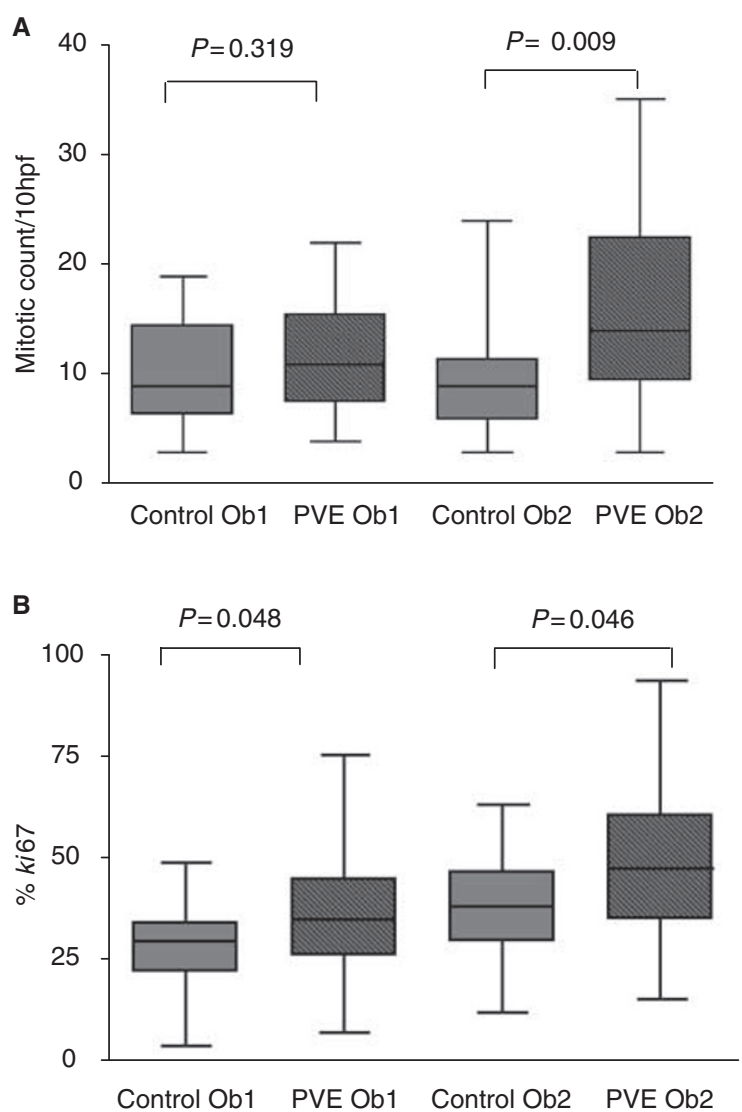

Figure 2 Mitotic count and Ki67 by two independent pathologists. (A) Mitotic count. (B) Ki67 count.

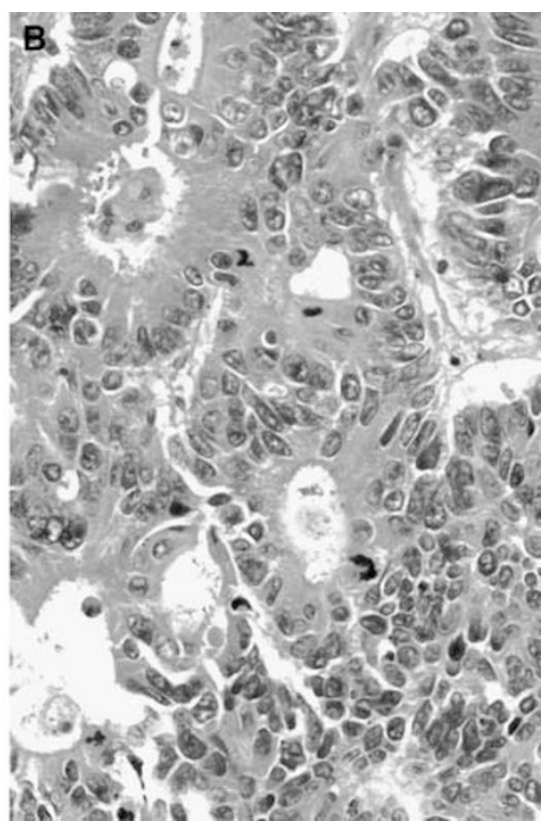

Figure 3 Typical example of mitosis expression (dark brown stain) in CRC metastases for a patient who had not undergone PVE (A) compared with that post PVE (B), suggesting high cancer-cell proliferation post PVE. 

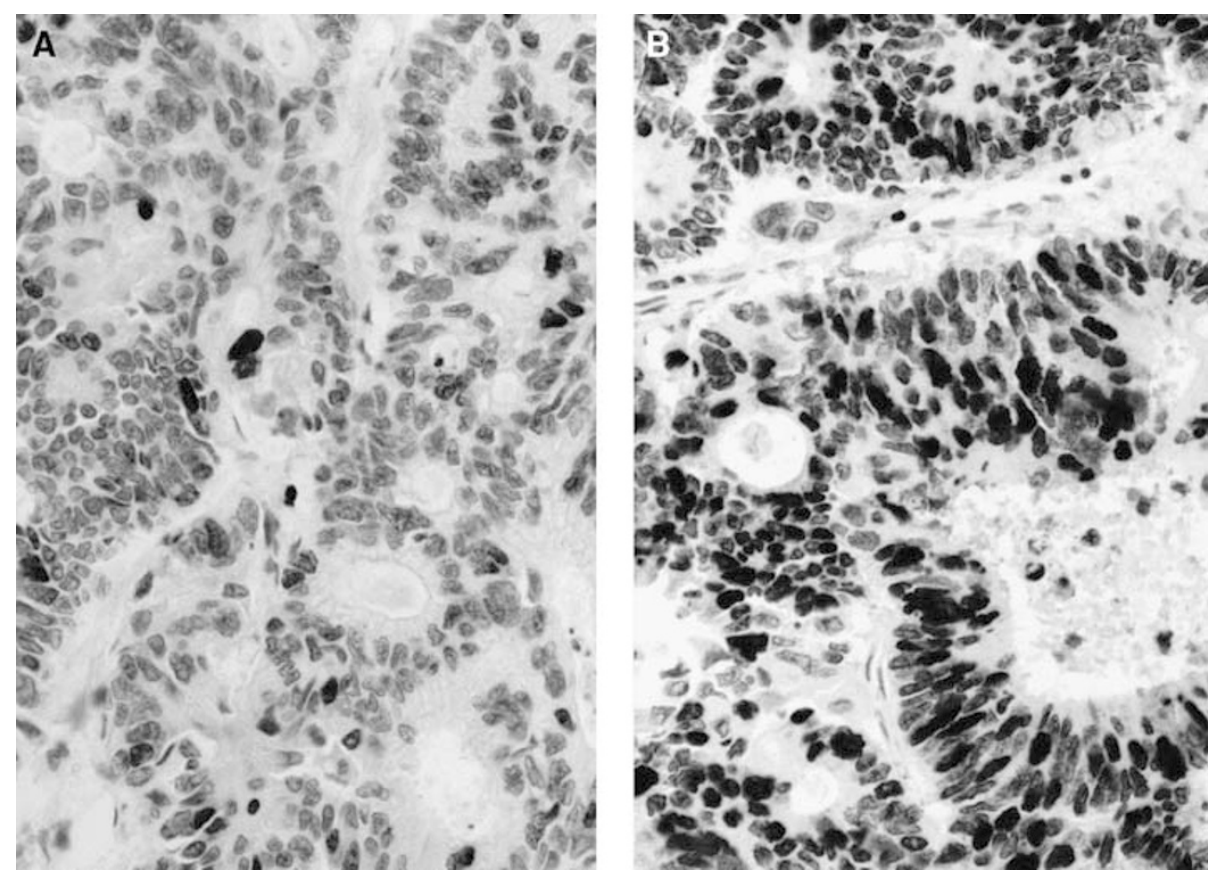

Figure 4 Typical example of Ki67 expression (dark brown stain) in CRC metastases for a patient who had not undergone PVE (A) compared with that post PVE (B), suggesting high cancer-cell proliferation post PVE.

Table 3 Subgroup analysis of tumour growth rate and Ki67 for synchronous and metachronous colorectal liver metastases

\begin{tabular}{|c|c|c|c|}
\hline & Control & PVE & $P$-value \\
\hline \multicolumn{4}{|c|}{ Tumour growth rate $\left(\mathrm{ml} \mathrm{day}^{-1}\right)$} \\
\hline Metachronous & $n=10$ & $n=9$ & \\
\hline Median & $-0.08(-0.57-0.07)$ & $0.42(-1.2-2.0)$ & \\
\hline Mean \pm s.d. & $-0.15 \pm 0.22$ & $0.41 \pm 0.88$ & 0.06 \\
\hline Synchronous & $n=10$ & $n=13$ & \\
\hline Median & $0.09(-0.26-0.66)$ & $0.51(-1.1-1.0)$ & \\
\hline Mean \pm s.d. & $0.01 \pm 0.26$ & $0.28 \pm 0.59$ & 0.15 \\
\hline \multicolumn{4}{|l|}{ Ki 67(\%) } \\
\hline Metachronous & $n=10$ & $n=9$ & \\
\hline Median & $21.85(3.8-35.8)$ & $37.40(6.9-75)$ & \\
\hline Mean \pm s.d. & $21.8 \pm 10.5$ & $41.5 \pm 20.4$ & 0.01 \\
\hline Synchronous & $n=10$ & $n=13$ & \\
\hline Median & $31.9(28.1-48.5)$ & $34(|1.9-6|)$ & \\
\hline Mean \pm s.d. & $33.3 \pm 6.1$ & $34 \pm 13.4$ & 0.89 \\
\hline
\end{tabular}

$\mathrm{PVE}=$ portal vein embolisation.

a 55\% 5-year survival for the control (no PVE) group. This figure compares favourably with reports from other centres suggesting a high-quality oncological surgery (Simmonds et al, 2006). The PVE group, despite having resection with clear margins, had a lower disease-free and long term survival. As the patient groups were well matched for cancer stage, this would strongly support the molecular evidence that PVE stimulates cancer cell division and, as a result, is associated with a reduced long term outcome.

In the present study, tumour growth was observed in patients following PVE despite pre- and post-PVE chemotherapy. Although pre- and-post operative chemotherapy may provide a small survival advantage, this should be short course and should avoid delaying surgical intervention (Nordlinger et al, 2007). In the light of increased hepatic arterial flow following PVE, which may be contributing to tumour growth, there is a logical reason for anti-angiogenic agents, such as Bevacizumab, along with routine chemotherapy (Hurwitz et al, 2005; Saltz et al, 2007) to cover the peri PVE period. This possibility requires evaluation in a prospective study.

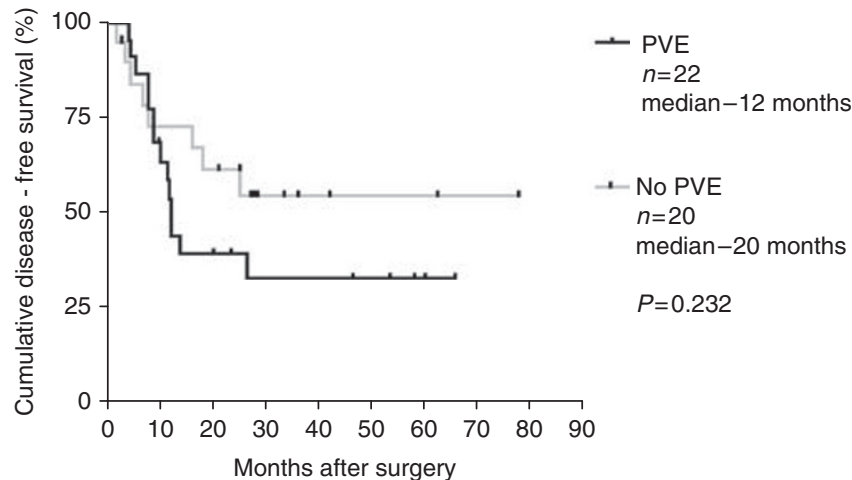

Figure 5 Disease-free survival after liver resection for colorectal metastases with and without prior PVE.

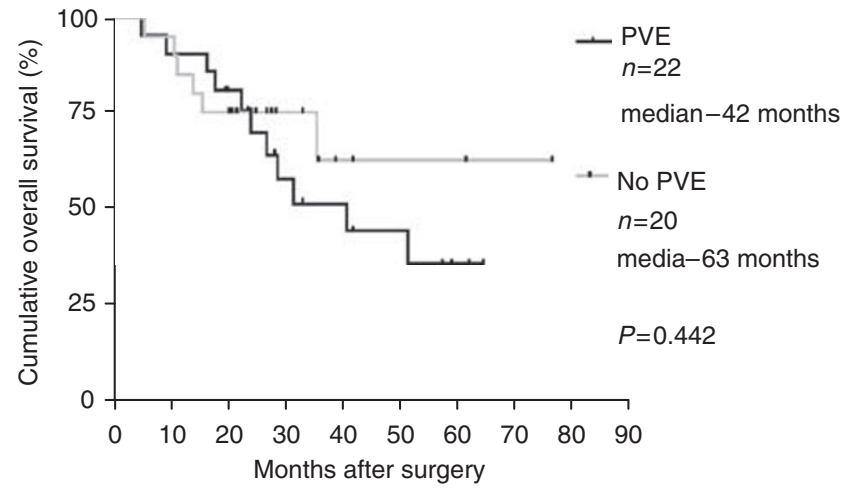

Figure 6 Overall survival after liver resection for colorectal metastases with and without prior PVE.

In conclusion, although PVE appears to benefit patients by facilitating liver resection in those who would be considered inoperable because of insufficient future liver remnant volume, 
there are concerns of stimulated tumour growth and inferior long term survival. Patients for PVE should be selected carefully and PVE should be avoided in patients with an adequate future liver remnant. At present, selection of patients for PVE is based on CT/MRI volumetry, and $30 \%$ of future liver remnant volume is considered adequate in patients with normal liver and $40 \%$ in patients with

\section{REFERENCES}

Abdalla EK, Hicks ME, Vauthey JN (2001) Portal vein embolization: rationale, technique and future prospects. Br J Surg 88: 165-175

Archer SG, Gray BN (1989) Vascularization of small liver metastases. Br J Surg 76: $545-548$

Beal I, Anthony S, Papadopoulou A, Huthins R, Fusai K, Begent R, Tibballs J, Davidson BR (2006) The effect of chemotherapy in patients undergoing portal vein embolisation prior to hepatic resection for colorectal liver metastases. Br J Radiol 79(942): 473-478

Braun L, Mead JE, Panzica M, Mikumo R, Bell GI, Fausto N (1988) Transforming growth factor beta mRNA increases during liver regeneration; a possible paracrinemechanism of growth regulation. Proc Natl Acad Sci USA 85: 1539-1543

Denys AL, Abehsera M, Leloutre B, Sauvanet A, Vilgrain V, O’Toole O, Belghiti J et al. (2000) Intrahepatic hemodynamic changes following portal vein embolization: a prospective Doppler study. Eur Radiol 10: 1703-1707

Dinant S, de Graaf W, Verwer BJ, Bennink RJ, van Lienden KP, Gouma DJ, van Vliet AK, van Gulik TM (2007) Risk assessment of posthepatectomy liver failure using hepatobiliary scintigraphy and CT volumetry. $\mathrm{J} \mathrm{Nucl}$ Med 48: 685-692

Elias D, De Baere T, Roche A, Mducreux, Leclere J, Lasser P (1999) During liver regeneration following right portal embolization the growth rate of liver metastases is more rapid than that of the liver parenchyma. $\mathrm{Br} \mathrm{J}$ Surg 86: $784-788$

Going JJ (1994) Efficiently estimated histologic cell counts. Hum Pathol 25(4): $333-336$

Hurwitz HI, Fehrenbacher L, Hainsworth JD, Heim W, Berlin J, Holmgren E, Hambleton J, Novotny WF, Kabbinavar F (2005) Bevacizumab in combination with fluorouracil and leucovorin: an active regimen for first-line metastatic colorectal cancer. J Clin Oncol 23: 3502

Kokudo N, Tada K, Seki M et al. (2001) Proliferative activity of intrahepatic colorectal metastases after preoperative hemihepatic portal vein embolization. Hepatology 34: 267-272

Kusaka K, Imamura H, Tomiya T, Takayama T, Makuuchi M (2006) Expression of transforming growth factor-alpha and -beta in hepatic lobes after hemihepatic portal vein embolization. Dig Dis Sci 51(8): 1404 - 1412. Epub 13 July 2006.

Melendez J, Ferri E, Zwillman M, Fischer M, DeMatteo R, Leung D, Jarnagin W, Fong Y, Blumgart LH (2001) Extended hepatic resection: a 6-year retrospective study of risk factors for perioperative mortality. $J$ Am Coll Surg 192: $47-53$

Mueller L, Grotelueschen R, Meyer J, Vashist YK, Abdulgawad A, Wilms C, Hillert C, Rogiers X, Broering DC (2003) Sustained function in atrophying liver tissue after portal branch ligation in the rat. J Surg Res 114: $146-155$

Mueller L, Hillert C, Möller L, Krupski-Berdien G, Rogiers X, Broering DC (2008) Major hepatectomy for colorectal metastases: is preoperative portal occlusion an oncological risk factor? Ann Surg Oncol 15(7): 1908-1917

Nabeshima K, Shimano Y, Inoue T, Itoh H, Kataoka H, Koono M (1998) Hepatocyte growth factor/scatter factor induces not only scattering but also cohort migration of human colorectal adenocarcinoma cells. Int J Cancer 78: $750-759$ abnormal liver function (Abdalla et al, 2001). Incorporating hepatic functional studies, such as hepatic scintigraphy (Dinant et al, 2007) and biopsy of normal liver, to evaluate histological abnormality (steatosis, steatohepatitis and cholestasis) in patients with borderline future liver remnant will provide further information on the quality of the residual liver and may avoid unnecessary PVE.

Nagino M, Nimura Y, Kamiya J, Kanai M, Hayakawa N, Yamamoto $\mathrm{H}$ (1998) Immediate increase in arterial blood flow in embolized hepatic segments after portal vein embolization: CT demonstration. Am J Roentgenol 171: 1037-1039

Nordlinger B, Sorbye H, Glimelius B, Poston GJ, Schlag PM, Rougier P, Bechstein WO, Primrose JN, Walpole ET, Finch-Jones M, Jaeck D, Mirza D, Parks RW, Collette L, Praet M, Bethe U, Van Cutsem E, Scheithauer W, Gruenberger T; EORTC Gastro-Intestinal Tract Cancer Group; Cancer Research UK; Arbeitsgruppe Lebermetastasen und-tumoren in der Chirurgischen Arbeitsgemeinschaft Onkologie (ALM-CAO); Australasian Gastro-Intestinal Trials Group (AGITG); Fédération Francophone de Cancérologie Digestive (FFCD) (2008) Perioperative chemotherapy with FOLFOX4 and surgery versus surgery alone for resectable liver metastases from colorectal cancer (EORTC Intergroup trial 40983): a randomised controlled trial. Lancet 371(9617): $1007-1016$

Pamecha V, Glantzounis G, Davies N, Fusai G, Sharma D, Davidson B (2009) Long-Term Survival and Disease Recurrence Following Porta Vein Embolisation Prior to Major Hepatectomy for Colorectal Metastases. Ann Surg Oncol, 6 January 2009 [Epub ahead of print]

Peeters CF, de Waal RM, Wobbes T, Westphal JR, Ruers TJ (2006) Out growth of human liver metastases after resection of the primary colorectal tumour: a shift in the balance between apoptosis and proliferation. Int J Cancer 119(6): 1249-1253

Saltz LB, Clarke S, Díaz-Rubio E, Scheithauer W, Figer A, Wong R, Koski S, Lichinitser M, Yang TS, Rivera F, Couture F, Sirzén F, Cassidy J (2008) Bevacizumab in combination with oxaliplatin-based chemotherapy as first-line therapy in metastatic colorectal cancer: a randomized phase III study. J Clin Oncol 26(12): 2013-2019

Schindl MJ, Redhead DN, Fearon KC, Garden OJ, Wigmore SJ (2005) Edinburgh Liver Surgery and Transplantation Experimental Research Group (eLISTER). The value of residual liver volume as a predictor of hepatic dysfunction and infection after major liver resection. Gut 54(2): $289-296$

Simmonds PC, Primrose JN, Colquitt JL, Garden OJ, Poston GJ, Rees M (2006) Surgical resection of hepatic metastases from colorectal cancer. Br J Cancer 94(7): 982 - 999

Uemura T, Miyazaki M, Hirai R, Matsumoto H, Ota T, Ohashi R, Shimizu N et al. (2000) Different expression of positive and negative regulators of hepatocyte growth in growing and shrinking hepatic lobes after portal vein branch ligation in rats. Int J Mol Med 5: 173-179

Ueno S, Aikou T, Tanabe G, Kobayashi Y, Hamanoue M, Mitsuse S, Kawaida K, Nakamura T (1996) Exogenous hepatocyte growth factor markedly stimulates liver regeneration following portal branch ligation in dogs. Cancer Chemother Pharmacol 38: 233-237

Weber JC, Nakano H, Bachellier P, Oussoultzoglou E, Inoue K, Shimura H, Wolf P, Chenard-Neu MP, Jaeck D (2001) Is a profileration index of cancer cells a reliable prognostic factor after hepatectomy in patients with colorectal liver metastases? Am J Surg 182(1): 81 - 88

Yokoyama Y, Nagino M, Nimura Y (2007) Mechanisms of hepatic regeneration following portal vein embolization and partial hepatectomy: a review. World J Surg 31(2): $367-374$ 